\title{
Intrapulmonary lymph node: a common and underrecognized tomography finding
}

\author{
Linfonodo intrapulmonar: um achado tomográfico \\ comum e pouco reconhecido
}

\author{
Bruno Hochhegger, Daniela Quinto dos Reis Hochhegger, Klaus Irion, \\ Ana Paula Sartori, Fernando Ferreira Gazzoni, Edson Marchiori
}

\section{To the Editor:}

We read with great interest the well-written manuscript by Melo et al., ${ }^{(1)}$ who analyzed clinical and radiological findings that influence the pathological diagnosis of solitary pulmonary nodule (SPN). They concluded that advanced age, greater maximum SPN diameter, and spiculated margins were significantly associated with the diagnosis of malignancy.

For radiologists and pulmonologists, SPNs continue to represent a major diagnostic challenge. Recent technological advances in imaging techniques and the widespread use of CT have increased the frequency of pulmonary nodule detection. ${ }^{(2)}$ Small nodules (1-2 $\mathrm{mm}$ in diameter) are commonly detected on CT images, and their clinical importance appears to differ markedly from that of larger nodules identified on chest X-rays. ${ }^{(2)}$ Thus, this enhanced detection has not affected the basic issue of distinguishing the status of a nodule, whether benign (requiring no specific approach) or indeterminate (potentially malignant), ${ }^{(2)}$ and most nodules are resected for diagnosis and determination of the appropriate treatment. ${ }^{(3)}$

Pulmonary lymph nodes are a common and underrecognized cause of a peripheral SPN. These lymph nodes are usually found at the bifurcation of the bronchi, before the fourth branch, where they are referred to as peribronchial lymph nodes. Lymph nodes are occasionally present within the lung parenchyma, where they are designated intrapulmonary lymph nodes (IPLNs) ${ }^{(3)}$ or perifissural nodules (PFNs).

The differentiation of IPLNs from other small pulmonary nodules on CT images is difficult although clinically important. In particular, the misinterpretation of a radiologically detected IPLN as a separate tumor nodule leads to overstaging and possible exclusion from indication for surgical treatment in patients with primary lung cancer. ${ }^{(3)}$ Several tomographic characteristics may aid in the differential diagnosis of an IPLN (Figure 1). These lymph nodes are oval, round, triangular, or trapezoidal, with sharply defined borders; they are almost always located below the level of the carina, predominantly in the subpleural regions of the lower lobes. They are frequently attached to the pleura or separated from the pleural surface by a few millimeters. ${ }^{(3-5)}$ IPLNs have thin linear attachments extending from the nodule to the pleura. These linear densities have been shown to represent ectatic lymphatic channels. ${ }^{(5)}$ De Hoop et al. ${ }^{(6)}$ recently reported that the growth rates of PFNs can reach those of malignant nodules, but no PFN in their study was malignant.

In conclusion, IPLNs are benign features that should be taken into consideration in the differential diagnosis of an SPN. Their identification might reduce the number of unnecessary surgeries and follow-up examinations.

\section{Bruno Hochhegger}

General Radiologist, Department of Pulmonology, Santa Casa Hospital Complex in Porto Alegre; and Professor of Radiology, Universidade Federal de Ciências da Saúde de Porto Alegre - UFSCPA, Federal University of Health Sciences of Porto Alegre - Porto Alegre, Brazil

Daniela Quinto dos Reis Hochhegger Radiologist, Department of Pulmonology, Santa Casa Hospital Complex in Porto Alegre, Porto Alegre, Brazil

\section{Klaus lrion}

Radiologist, Liverpool Heart and Chest Hospital, and Royal Liverpool 
(A)

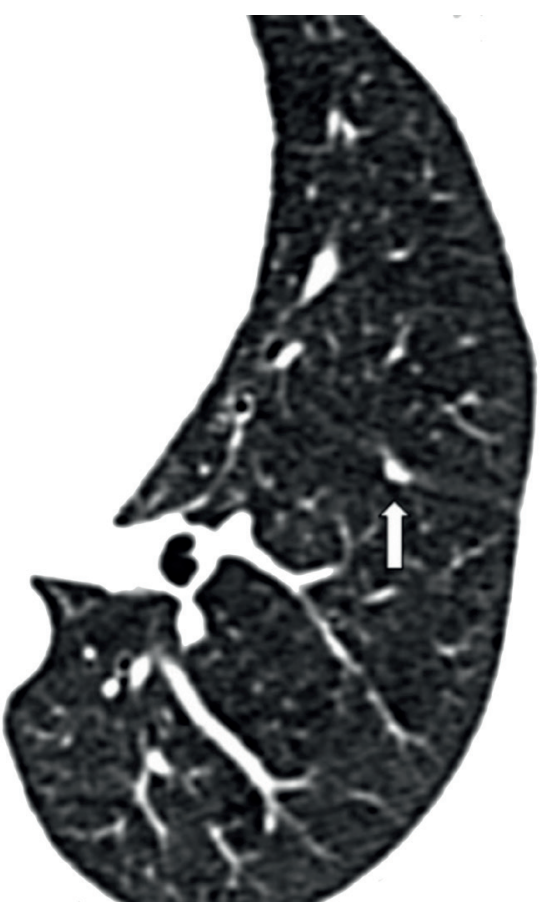

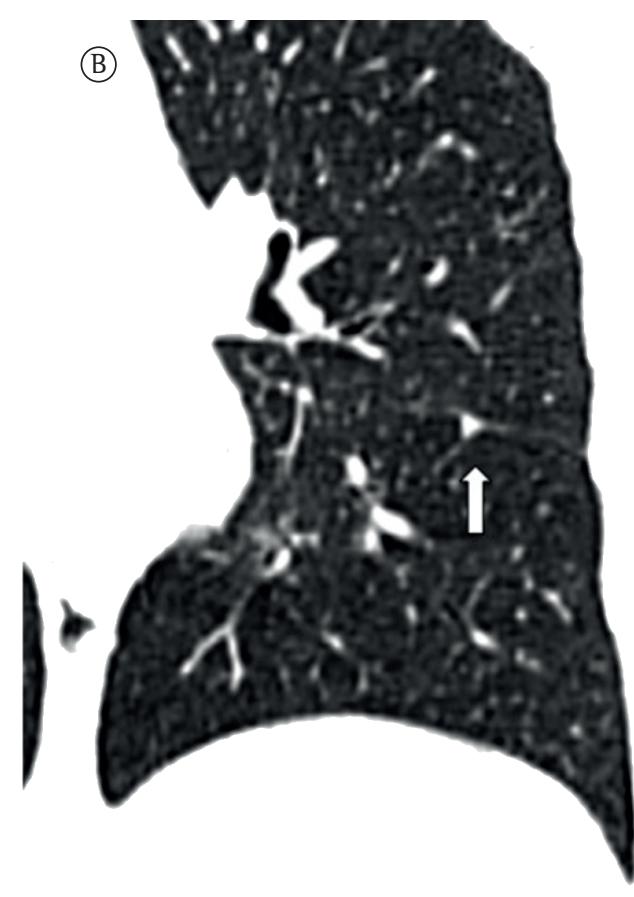

Figure 1 - $\ln$ A, an axial CT image of the chest (lung window) of a 53-year-old man. A triangular intrapulmonary lymph node $(3 \times 4 \mathrm{~mm})$ is attached to the pleural fissure. In B, a coronal CT image (lung window) showing the triangular shape and septal contact (arrow) of the intrapulmonary lymph node.

and Broadgreen University Hospital, Liverpool, United Kingdom

\section{Ana Paula Sartori}

Radiologist, Department of

Pulmonology, Santa Casa Hospital

Complex in Porto Alegre, Porto Alegre, Brazil

\section{Fernando Ferreira Gazzoni}

Radiologist, Department of Radiology,

Porto Alegre Hospital de Clínicas, Porto Alegre, Brazil

\section{Edson Marchiori}

Associate Professor, Department of Radiology, Federal University of Rio de Janeiro, Rio de Janeiro, Brazil

\section{References}

1. Melo CB, Perfeito JA, Daud DF, Costa Júnior Ada S, Santoro IL, Leão LE. Analysis and validation of probabilistic models for predicting malignancy in solitary pulmonary nodules in a population in Brazil. J Bras Pneumol. 2012;38(5):559-65. http://dx.doi.org/10.1590/S180637132012000500004 PMid:23147047

2. Marchiori E, lrion KL. Advances in the radiological diagnosis of pulmonary nodules. J Bras Pneumol. 2008;34(1):2-3. http://dx.doi.org/10.1590/S1806-37132008000100002 PMid:18278369

3. Wang CW, Teng YH, Huang CC, Wu YC, Chao YK, Wu CT. Intrapulmonary lymph nodes: computed tomography findings with histopathologic correlations. Clin lmaging. 2013;37(3):487-92. http://dx.doi.org/10.1016/j. clinimag.2012.09.010 PMid:23102925

4. Takenaka M, Uramoto H, Shimokawa H, So T, Hanagiri $\mathrm{T}$, Aoki T, et al. Discriminative features of thin-slice computed tomography for peripheral intrapulmonary lymph nodes. Asian J Surg. 2013;36(2):69-73. http:// dx.doi.org/10.1016/j.asjsur.2012.11.005 PMid:23522758

5. Shaham D, Vazquez M, Bogot NR, Henschke Cl, Yankelevitz DF. CT features of intrapulmonary lymph nodes confirmed by cytology. Clin lmaging. 2010;34(3):185-90. http:// dx.doi.org/10.1016/j.clinimag.2009.05.005 PMid:20416482

6. de Hoop B, van Ginneken B, Gietema H, Prokop M. Pulmonary perifissural nodules on $\mathrm{CT}$ scans: rapid growth is not a predictor of malignancy. Radiology. 2012;265(2):611-6. http://dx.doi.org/10.1148/ radiol.12112351 PMid:22929331 